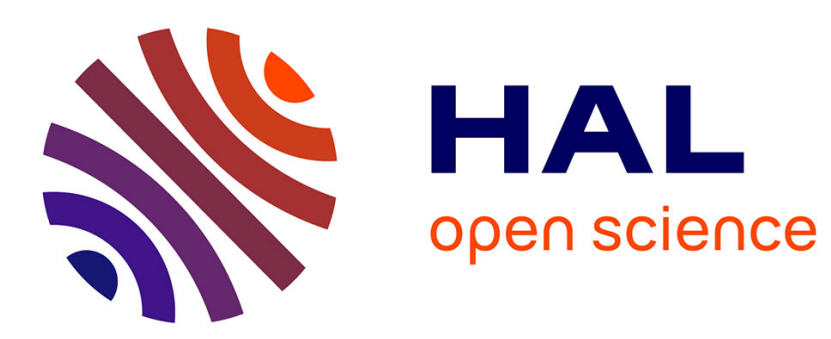

\title{
Effect of fourteen days of acclimatization on athletic performance in tropical climate
}

Bruno Voltaire, Olivier Galy, Olivier Costes, Sébastien Racinais, André Callis, Olivier Hue

\section{- To cite this version:}

Bruno Voltaire, Olivier Galy, Olivier Costes, Sébastien Racinais, André Callis, et al.. Effect of fourteen days of acclimatization on athletic performance in tropical climate. Canadian Journal of Applied Physiology, 2002, 27 (6), pp.551-562. 10.1139/h02-031 . hal-00720075

\section{HAL Id: hal-00720075 https://hal.univ-antilles.fr/hal-00720075}

Submitted on 23 Jul 2012

HAL is a multi-disciplinary open access archive for the deposit and dissemination of scientific research documents, whether they are published or not. The documents may come from teaching and research institutions in France or abroad, or from public or private research centers.
L'archive ouverte pluridisciplinaire HAL, est destinée au dépôt et à la diffusion de documents scientifiques de niveau recherche, publiés ou non, émanant des établissements d'enseignement et de recherche français ou étrangers, des laboratoires publics ou privés. 


\title{
Effect of Fourteen Days of Acclimatization on Athletic Performance in Tropical Climate
}

\author{
B. Voltaire, O.Galy, O. Costes, S. Racinais, A. Callis, and O. Hue
}

\section{Catalog Data}

Voltaire, B., Galy, O., Costes, O., Racinais, S., Callis, A., and Hue, O. (2002). Effect of fourteen days of acclimatization on athletic performance in tropical climate. Can. J. Appl. Physiol. 27(6): 551-562. (C2002 Canadian Society for Exercise Physiology.

Keywords: triathletes, aerobic performance, jet lag, dehydration, hyperthermia Mots-clés: triathlètes, performance aérobie, décalage horaire, déshydratation, hyperthermie

\begin{abstract}
Résumé
In order to study the acclimatization process over 14 days of exposure to tropical climate, 9 triathletes performed 4 outdoor indirect continuous multistage tests in both thermoneutral and tropical conditions. The thermoneutral test $\left(T N, 14{ }^{\circ} \mathrm{C}, 45 \% \mathrm{rh}\right)$ was performed before traveling to the tropical area (Martinique, FWI). The tropical tests were performed 2, 8, and 14 days after arrival $\left(32.9{ }^{\circ} \mathrm{C}, 78 \% \mathrm{rh}\right)$. During each trial, we measured tympanic temperature, sweat rate, body mass loss, heart rate (HR), and performance. The results showed that 1) the mean tympanic temperature was greater in $T 2(\mathrm{P}<.001), T 8(\mathrm{P}<.01)$ and T14 ( $\mathrm{P}<.01)$ than in TN and significantly lower in T14 than in T2 (P <.05); 2) the mean sweat rate was significantly greater $(\mathrm{P}<.001)$ in T2, T8 and T14 than in TN and significantly greater ( $\mathrm{P}<.05)$ in $T 8$ and $T 14$ than in T2; 3) the body mass loss after trials was significantly greater $(\mathrm{P}<.001)$ in T2, T8 and T14 than in TN and significantly greater $(\mathrm{P}<.05)$ in T8 and T14 than in T2; 4) the mean HR and HR at rest were significantly higher $(\mathrm{P}<.005)$ in T2 than in TN, T8, T14 and the mean HR was significantly lower $(\mathrm{P}<.05)$ in T14 than in the other trials; and 5) the performance time was significantly lower in $T 2(\mathrm{P}<$ $0.02), T 8(P<0.03)$ and T14 $(\mathrm{P}<0.05)$ than in TN. We concluded that 14 days of exposure
\end{abstract}

B. Voltaire, O. Galy, S. Racinais, and O. Hue are with the Laboratoire ACTE, UFRSTAPS des Antilles et de la Guyane, Campus de Fouillole, 97159 Pointe à Pitre, France (FWI); O. Costes is with the Laboratoire de Physiologie des Interactions, CHU Arnaud de Villeneuve, $\mathbf{3 4 0 8 0}$ Montpellier, France; and A. Callis is with the Laboratoire de Biochimie B, CHU Guy de Chaulliac, 34080 Montpellier, France. 
to tropical climate led to changes in physiological parameters but were still insufficient to ensure complete acclimatization in well-trained athletes. The hot/wet climate induced impairment of physiological responses and performance that were still evident on the 14th day.

Afin de déterminer les processus d'acclimatation obtenus après 14 jours d'exposition en climat tropical, 9 triathlètes ont effectué quatre tests de terrain, indirect et continu en ambiance thermique neutre et en climat tropical. Les sujets ont réalisé le test en conditions de neutralité thermique $\left(\mathrm{TN}, 14{ }^{\circ} \mathrm{C}, 45 \% \mathrm{hr}\right)$ avant leur voyage en milieu tropical (Martinique, Antilles françaises). Les tests en conditions tropicales ont été réalisés 2, 8 et 14 jours après leur arrivée $\left(32.9^{\circ} \mathrm{C}, 78 \% \mathrm{hr}\right)$. Au cours de chaque épreuve, nous avons relevé la température tympanique, le débit sudoral, la perte de masse corporelle, la fréquence cardiaque et la performance. Les résultats ont montré que 1) la température tymapnique moyenne était supérieure lors de T2 $(\mathrm{P}<.001), T 8(\mathrm{P}<.01)$ et $T 14(\mathrm{P}<.01)$ par rapport à TN, et significativement inférieure à T14 qu'à T2 $(\mathrm{P}<.05) ; 2)$ le débit sudoral moyen était significativement plus élevé $(\mathrm{P}<.01)$ au cours de T2, T8 et T14 comparé à TN et significativement supérieur $(\mathrm{P}<.05)$ lors de T14 et T8 comparé à $T 2 ; 3)$ la perte de masse corporelle après l'exercice était significativement supérieure $(\mathrm{P}<.001)$ lors de T2, T8 et T14 comparée à TN et significativement plus importante à T8 et T14 qu'à T2 (P <.05); 4) la fréquence cardiaque moyenne et celle de repos était plus élevée $(\mathrm{P}<.005)$ à $T 2$ qu'à $T N$, T8, T14 et la fréqunce cardiaque moyenne était significativement plus basse $(\mathrm{P}<.05)$ à T14 qu'au cours des autres épreuves ; 5) le temps de performance était diminué lors de T2 (P < $.02), T 8(\mathrm{P}<.03)$ et T14 ( $\mathrm{P}<.05)$ comparé à TN. Nous en avons conclu que 14 jours d'exposition au climat tropical ont donné lieu à des adaptations physiologiques qui restent insuffisantes pour une acclimatation complète chez des athlètes bien entraînés. Le climat chaud et humide lors de l'exercice altère les réponses physiologiques et la performance, altérations qui subsistent après 14 jours d'acclimatation.

\section{Introduction}

The detrimental effect of high environmental temperature on aerobic performance has been well documented (Galloway and Maughan, 1997; Morris et al., 1998) and it is well known that exercise-heat acclimatization involves a complex set of adaptations that serve to reduce physiological strain and improve ability to exercise in a hot environment (Armstrong and Maresh, 1991). However, although considerable information has been gathered on the physiological adaptation to hot/dry climates, information on acclimation to hot/wet climates is still limited (Shapiro et al., 1998). Earlier studies, cited by Pandolf (1998), have demonstrated that nearly complete heat acclimation for both hot/dry and hot/humid environments occurs after 7 to 10 days of exposure. In agreement with these earlier studies, Nielsen (1998) showed that physiological adaptations were similar in humid and dry heat when subjects exercised daily for 8-12 consecutive days. Furthermore, $66 \%$ to $75 \%$ of the physiological adjustments were seen in 4 to 6 days (Pandolf et al., 1988; Sawka et al., 1996), and it has been suggested that high levels of aerobic capacity aid the individual to acclimatize (Pandolf et al., 1988). The current recommendation is that competitive athletes expected to participate in an event involving heat stress should acclimatize/train in the heat for at least 5 days beforehand to help maximize performance (Pandolf, 1998). 
The above results are in contrast to a few recent studies specifically comparing the effects of acclimation in a hot/dry climate to those created by a vapor barrier suit (NBC suit) that creates a hot/wet microclimate regardless of the ambient conditions (Shapiro et al., 1998). The results showed that under the same exercise intensity, the strain was higher (rectal temperature and heart rate were higher by about $1^{\circ} \mathrm{C}$ and $30 \mathrm{bpm}$, respectively) when subjects were tested with the suit. A similar study obtained the same results even after 10 days of acclimation, thus clearly demonstrating the difference between hot/dry and hot/wet acclimation conditions (Aoyagi et al., 1994). The data to date on hot-wet conditions indicate that the high required evaporative cooling exceeds the evaporative capacity of the environment (Shapiro et al., 1998), thereby inducing an irreversible decrease in performance (Nielsen, 1996). Unfortunately, these data have only been gathered in laboratory (Aoyagi et al., 1994; Cheung and MacLellan, 1998a, 1998b) or they have been extrapolated (Nielsen, 1996). Despite the fact that these conditions are found naturally in a tropical climate, studies exploring the physiological responses elicited by a hot/wet climate during outdoor testing are very few.

The aim of the present study was thus to investigate whether 14 days of acclimatization to hot/wet conditions (tropical climate) would be sufficient for elite triathletes to achieve the same level of performance as in thermoneutral conditions.

\section{Material and Method}

\section{SUBJECTS}

Nine young elite triathletes ( 8 males, 1 female) voluntarily participated in this investigation. All were members of the French national athletic training center in Montpellier, France. They were in the competitive period at the time of the study (mean training volume: $16.4 \pm 1.4 \mathrm{~h} \cdot \mathrm{wk}^{-1}$ ). Anthropometric and physiological data are reported in Table 1. All subjects were informed of the purpose of the study and gave written consent in accordance with the regional ethics committee before participating.

Table 1 Anthropometric and Physiological Data of the Subjects $(N=9)$

\begin{tabular}{lccrrrrrr}
\hline $\begin{array}{l}\text { Age } \\
\text { (yrs })\end{array}$ & $\begin{array}{c}\mathrm{BM} \\
(\mathrm{kg})\end{array}$ & $\begin{array}{c}\text { Height } \\
(\mathrm{cm})\end{array}$ & $\begin{array}{c}\mathrm{BFM} \\
(\%)\end{array}$ & $\begin{array}{c}\dot{\mathrm{VO}}_{2 \max } \\
\left(\mathrm{ml} \cdot \mathrm{kg}^{-1}\right. \\
\left.\cdot \mathrm{min}^{-1}\right)\end{array}$ & $\begin{array}{c}\mathrm{HR}_{\max } \\
(\mathrm{bpm})\end{array}$ & $\begin{array}{c}\mathrm{HR}_{\mathrm{A}} \\
(\mathrm{bpm})\end{array}$ & $\begin{array}{r}\mathrm{HR}_{\mathrm{AN}} \\
(\mathrm{bpm})\end{array}$ & $\begin{array}{c}\mathrm{MAV} \\
\left(\mathrm{km} \cdot \mathrm{h}^{-1}\right)\end{array}$ \\
\hline 22.7 & 70.0 & 178.3 & 10.3 & 63.5 & 184 & 152 & 170 & 20.7 \\
1.0 & 3.0 & 2.9 & 0.3 & 1.6 & 3 & 3 & 3 & 0.4 \\
\hline
\end{tabular}

Values are mean \pm SEM. BM, body mass; BFM, body fat mass; $\dot{\mathrm{V}} \mathrm{O}_{2 \max }$, maximal aerobic power; $\mathrm{HR}_{\max }$, maximal heart rate noted at $\dot{\mathrm{VO}}_{2 \max } ; \mathrm{HR}_{\mathrm{A}}$, heart rate at aerobic threshold; $\mathrm{HR}_{\mathrm{AN}}$, heart rate at anaerobic threshold; MAV, maximal aerobic velocity measured at $\dot{\mathrm{V}} \mathrm{O}_{2 \max }$ during laboratory test. 


\section{TESTING PROTOCOL}

Each subject performed a 5-trial protocol that took place over 5 consecutive weeks. The tests were conducted at the same time of day $(10: 30 \mathrm{am})$ and there were at least 6 days between trials. All subjects were familiarized with treadmill running prior to testing. For the 2 days before trials in thermoneutral conditions and during their stay in the tropical climate, subjects were asked to follow a normal diet in order to avoid $\mathrm{CHO}$ depletion during the trials. Although the subjects followed a daily training program in tropical climate, they were also asked to avoid intense physical activity during the $24 \mathrm{~h}$ before each trial. Anthropometric and physiological parameters (Table 1) were measured during a pre-test which was an incremental running test performed in laboratory in thermoneutral conditions $\left(20^{\circ} \mathrm{C}, 40 \%\right.$ $\mathrm{rh}$ ). Trial 1 (TN) was an outdoor incremental running test performed in thermoneutral conditions (TN: $14{ }^{\circ} \mathrm{C}, 45 \% \mathrm{rh}$ ); trial 2 (T2), trial 3 (T8) and trial 4 (T14), were also outdoor incremental running tests performed in tropical climate, respectively 2 days, 8 days and 14 days after arrival. The average $\mathrm{T}_{\mathrm{db}}$ was $32.9^{\circ} \mathrm{C}\left[31-35.7^{\circ} \mathrm{C}\right.$ ] and the average $\mathrm{rh}, 78 \%$ [75-82\% rh].

\section{LABORATORY TEST}

The incremental treadmill (Gymrol 1800, Gymrol, Roche La Molière, France) test began at $7 \mathrm{~km} \cdot \mathrm{h}^{-1}$ for one minute at $0 \%$ grade. The speed was then increased by 1 $\mathrm{km} \cdot \mathrm{h}^{-1}$ every minute up to a maximum speed of $18 \mathrm{~km} \cdot \mathrm{h}^{-1}$. The speed was then held constant and the grade was increased by $1 \%$ every minute until the subject reached exhaustion. The triathlete's peak treadmill velocity was considered to be the highest graded speed he or she maintained for $60 \mathrm{~s}$, using the formula of Margaria et al. (1963).

\section{Peak treadmill speed $=$ Speed $+(\%-1.5) / 1.5$}

where Speed is the maximal velocity attained by the subject in $\mathrm{km} \cdot \mathrm{h}^{-1}, \%$ is the grade attained at Speed and 1.5 is the grade at which a rise of $1.5 \%$ corresponds to a rise of $1 \mathrm{~km} \cdot \mathrm{h}^{-1}$.

When a subject was unable to complete a full $60 \mathrm{~s}$ at required speed, peak treadmill running speed was determined as a fraction of the final graded speed added to the velocity of the immediately preceding complete graded speed.

The outdoor incremental test was an indirect continuous running multistage test called the Université de Montréal track test (Léger and Boucher, 1980). Subjects ran along markers placed every $20 \mathrm{~m}$ on a 400-m track and were paced by a audible cue. The interval between cues decreased gradually (every minute) and subjects had to increase their speed $\left(0.5 \mathrm{~km} \cdot \mathrm{h}^{-1} \cdot \mathrm{min}^{-1}\right)$ to keep pace with the cue. Subjects wore a tee-shirt and shorts during the outdoor tests in tropical conditions.

During these tests, heart rate (HR) was monitored with a heart rate monitor (Polar Accurex Plus, Polar Electro, Kempele, Finland) with recording every $5 \mathrm{~s}$.

Tympanic temperature $\left(\mathrm{T}_{\mathrm{tym}},{ }^{\circ} \mathrm{C}\right)$ was recorded before exercise, immediately at the end of exercise and at the 10th min, 20th min and 30th min of recovery in the ear using a thermometer (Thermoscan Braun, Thermoscan, Inc, San Diego, CA, USA) that measures infrared temperature generated by the eardrum. Since the tympanum shares a common blood supply with the hypothalamus, $\mathrm{T}_{\mathrm{tym}}$ has been pro- 
posed as a surrogate measure of hypothalamic temperature. In fact, Bricknell (1997) demonstrated in an evaluation of infrared thermometry for thermal physiology research that the slope of the regression line between tympanic temperature and core temperature measurements was 0.9967 with a correlation coefficient of 0.706 . It has been demonstrated to be accurate enough to evaluate temperature changes during fields trials (Bricknell 1997). In the present study, the $\mathrm{T}_{\mathrm{tym}}$ was measured by the same investigator.

Sweat rate $\left(\mathrm{SR}_{\mathrm{f}}, \mathrm{mL} \cdot \mathrm{min}^{-1} \cdot \mathrm{cm}+\cdot^{-1}\right)$ was measured in the following manner: sweat was collected from the forehead, which had first been washed with distilled water and dried. The quantity was measured using absorbent paper of 50 $\mathrm{cm}+$, which was sealed in hermetic plastic bags before and after exercise (Pilardeau, 1995). Changes in paper weight were measured with a scale of very high sensitivity $\left( \pm 1.10^{-4} \mathrm{~g}\right.$ ) (Scaltec SBA 31, Scaltec Instruments GmBH, RudolphDiesel-Strasse, Heiligenstadt, Germany). The sweat rate noted on the forehead was calculated as follows: $\mathrm{SR}_{\mathrm{f}}=(\mathrm{d}[\mathrm{bf}-\mathrm{af}] / \mathrm{t}) * 60$, where $\mathrm{d}[\mathrm{bf}-\mathrm{af}]$ is the difference in absorbent paper weight before and after exercise, $t$ is the time the absorbent paper stayed on the forehead, and 60 is the number of seconds in one minute. Mean sweat rate $\left(\mathrm{SRm}, \mathrm{L} \cdot \mathrm{h}^{-1}\right)$ was estimated by adjusting the SRf for the skin surface area covered by the absorbent paper multiplied by the body surface area estimated from the equation of Dubois and Dubois (1916).

Body mass loss $(\mathrm{kg})$ was measured on a scale by changes in nude body mass $\left( \pm 1.10^{-1} \mathrm{~kg}\right)$ (Planax Automatic, Teraillon, Chatou, France). The subjects were weighed in the same conditions before and after exercise.

\section{STATISTICAL ANALYSIS}

The results are expressed as means + SEM. Data for performance, sweat rate, body mass loss, temperature and heart rate were compared using a two-way analysis of variance (ANOVA) with repeated measures (situation, time). When significant results were obtained, post-hoc comparisons were made using the contrast method. Statistical significance was accepted at the $P<.05$ level.

\section{Results}

\section{TYMPANIC TEMPERATURE}

The mean temperature was greater in T2 $(P<.001)$, T8 $(P<.01)$ and T14 $(\mathrm{P}<.01)$ than in TN (Table 2$)$. The mean $\mathrm{T}_{\text {tym }}$ was significantly lower $(P>.05)$ in T14 than in T2. There was no significant difference in the temperature at rest (Figure 1); however, the temperature at the end of exercise and during recovery was greater in T2 $(P<.001)$, T8 $(P<.01)$ and T14 $(P<.01)$. The temperature at the 20th min of recovery was greater in T2 than in TN, T8 and T14 $(P<.01)$. Also, we noted no difference in $\mathrm{T}_{\text {tym }}$ between $\mathrm{T} 14$ and TN at the end of exercise; temperature at T14 was significantly greater than in TN only during recovery $(P<.01)$.

\section{SWEAT RATE}

Both the mean sweat rate (Table 2) and the sweat rate at the end of exercise (Figure 2 ) were significantly greater $(P>0.001)$ in T2, T8 and T14 than in TN. Moreover, 
Table 2 Physical, Physiological and Performance Values Noted in Thermoneutral Conditions (TN) and Two Days (T2), Eight Days (T8) and Fourteen Days (T14) After Arrival in Hot/Humid Climate

\begin{tabular}{lccccc}
\hline & $\begin{array}{l}\mathrm{T}_{\mathrm{tym}} \\
\left({ }^{\circ} \mathrm{C}\right)\end{array}$ & $\begin{array}{l}\mathrm{SR}_{\text {mean }} \\
\mathrm{L} \cdot \mathrm{h}^{-1}\end{array}$ & $\begin{array}{c}\mathrm{BM} \text { loss } \\
(\mathrm{kg})\end{array}$ & $\begin{array}{c}\mathrm{HR}_{\text {mean }} \\
(\mathrm{bpm})\end{array}$ & $\begin{array}{c}\mathrm{MAV} \\
\left(\mathrm{km} \cdot \mathrm{h}^{-1}\right)\end{array}$ \\
\hline $\mathrm{TN}$ & $37 \pm 0.5$ & $0 \pm 0$ & $0.18 \pm 0.05$ & $134 \pm 11$ & $19.02 \pm 0.41$ \\
$\mathrm{~T} 2$ & $37.8 \pm 0.3 *$ & $1.2 \pm 0.1 *$ & $0.41 \pm 0.06^{*}$ & $153 \pm 8^{*}$ & $18.02 \pm 0.62 *$ \\
$\mathrm{~T} 8$ & $37.7 \pm 0.4^{*}$ & $2.64 \pm 0.1 * \$$ & $0.9 \pm 0.09 * \$$ & $136 \pm 13$ & $18.58 \pm 0.54 *$ \\
$\mathrm{~T} 14$ & $37.4 \pm 0.4 * \$$ & $1.86 \pm 0.1 * \$$ & $0.7 \pm 0.08 * \$$ & $128 \pm 12 * *$ & $18.74 \pm 0.59 *$ \\
\hline
\end{tabular}

Values are means \pm SEM. *Indicates significant difference from TN values $(P<.05), \$$ indicates significant difference from T2 values $(P<.05)$, **indicates significant difference from TN, T2 and T8 values $(P<.05)$.

$\mathrm{T}_{\text {tym }}$, tympanic temperature; $\mathrm{SR}_{\text {mean }}$, mean sweat rate noted at the end of exercise expressed in $1 \cdot \mathrm{h}^{-1} ; \mathrm{BM}$, body mass; $\mathrm{HR}_{\text {mean }}$, mean heart rate; MAV, maximal aerobic velocity.

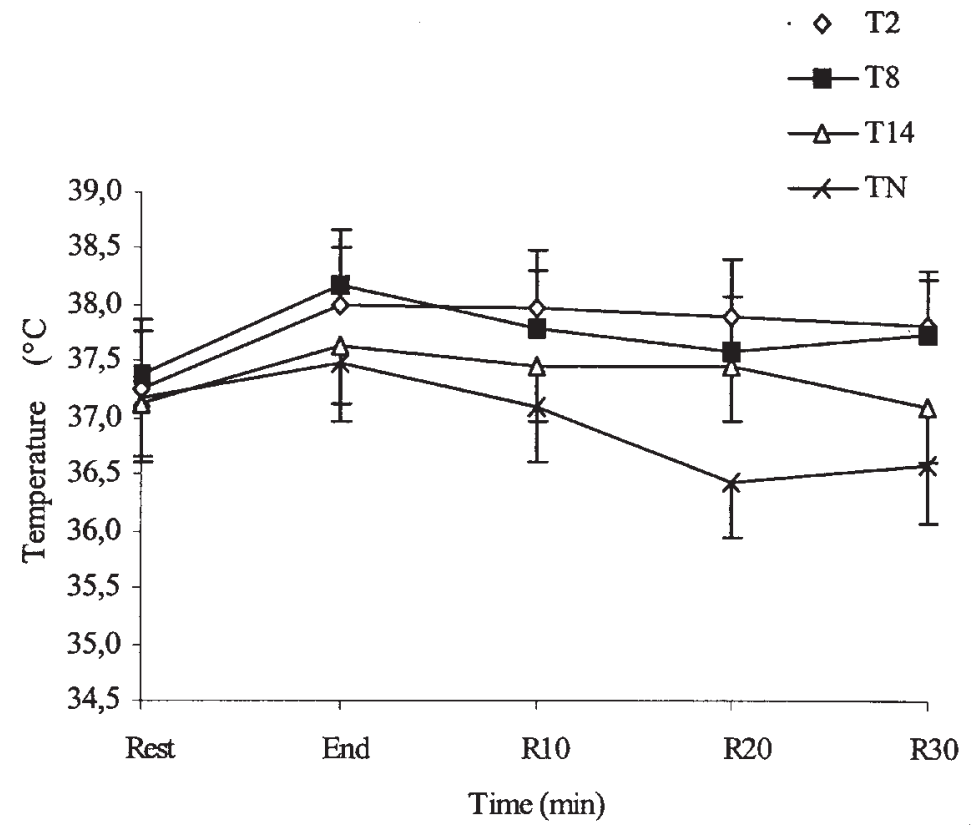

Figure 1. Tympanic temperature noted at rest, at the end of exercise and during recovery (at the 10th, 20th, and 30th min recovery; R10, R20, R30, respectively). *Indicates significant difference from TN values, $\$$ indicates significant difference from T2 values $(p<.05)$. 


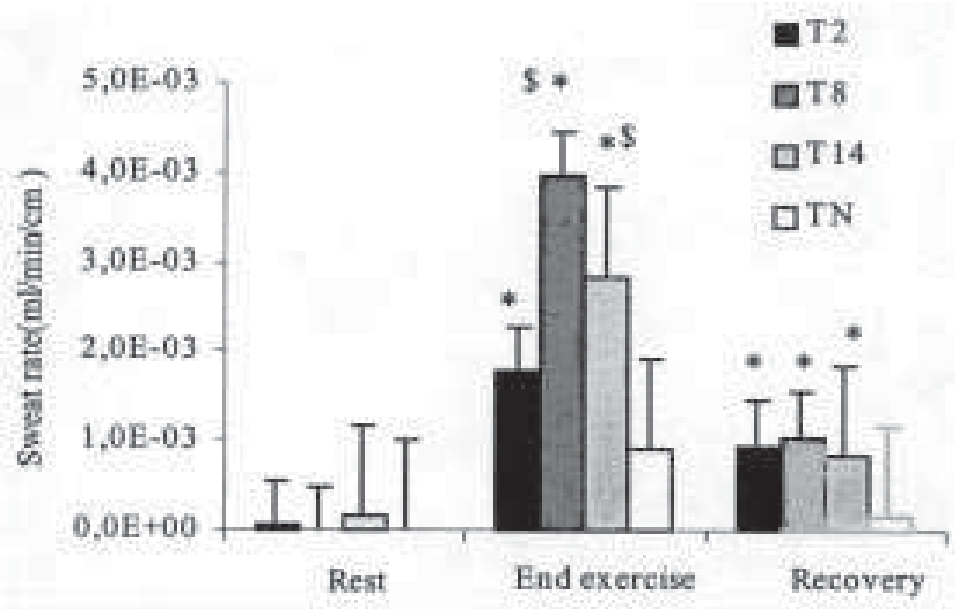

Figure 2. Sweat rate noted at rest, at the end of exercise and during recovery. *Indicates significant difference from TN values $(P<.05)$.

these were both significantly greater in T8 $(P<0.03)$ and T14 $(P<0.05)$ than in $\mathrm{T} 2$.

\section{BODY MASS LOSS}

The body mass loss after trials was significantly greater in T2 $(0.41 \pm 0.06 \mathrm{~kg}), \mathrm{T} 8$ $(0.9 \pm 0.09 \mathrm{~kg})$, and T14 $(0.7 \pm 0.08 \mathrm{~kg})$ than in TN $(0.18 \pm 0.05 \mathrm{~kg})(P<.001)$. Furthermore, body mass loss was significantly increased in T8 $(P<.03)$ and T14 $(P<.05)$ than in T2. The body mass losses are in concordance with the estimated mean sweat rate. There was no significant difference in body mass loss before exercise over the entire study period. The data are shown in Table 2.

\section{HEART RATE}

The mean HR (Table 2$)$ was significantly greater in T2 than in TN $(P<.001)$, T8 $(P<.005)$ and T14 $(P<.005)$. The HR at rest and during exercise (Figure 3$)$ was significantly higher in T2 than in TN, T8 and T14 before the $\mathrm{HR}_{\mathrm{AN}}(P<.005)$. The mean HR was significantly lower $(P<.05)$ in T14 than in TN, T2 and T8. At rest and up to the $\mathrm{HR}_{\mathrm{A}}$, the HR was equal in T8 and TN; however, from the $\mathrm{HR}_{\mathrm{A}}$ to $\mathrm{HR}_{\max }$, the $\mathrm{HR}$ was significantly greater in $\mathrm{T} 8$ than in TN. Under the $\mathrm{HR}_{\mathrm{A}}$, the $\mathrm{HR}$ was significantly lower $(P<.05)$ in T14 than in TN (Figure 3 ).

\section{PERFORMANCE}

The performance was significantly lower in T2 $\left(18.02 \pm 0.62 \mathrm{~km} \cdot \mathrm{h}^{-1} ; P<.02\right)$, T8 $\left(18.58 \pm 0.54 \mathrm{~km} \cdot \mathrm{h}^{-1} ; P<.03\right)$ and T14 $\left(18.74 \pm 0.59 \mathrm{~km} \cdot \mathrm{h}^{-1} ; P<.05\right)$ than in TN $\left(19.02 \pm 0.41 \mathrm{~km} \cdot \mathrm{h}^{-1}\right)$ (Table 2). 


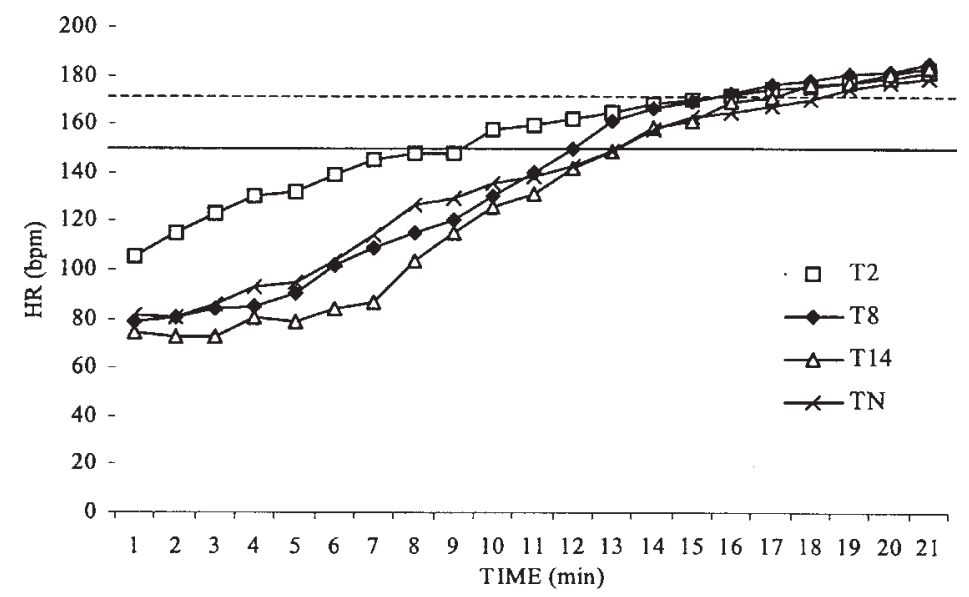

Figure 3. Heart rate noted during the trials.

\section{Discussion}

The main finding of this study was that 14 days of exposure to a hot/wet climate were insufficient to ensure complete acclimatization in elite triathletes. After 14 days, the physiological responses (i.e., temperature, sweat rate, body mass loss and heart rate) and performance level were significantly impaired when compared with the values reached in thermoneutral conditions during a maximal aerobic test. This provides new information on the physiological demand imposed by exercise under hot/wet conditions.

In a recent review, Manfredini et al. (1998) suggested that the alterations induced by westward flights are very few. Nevertheless, in the present study, which included a 6-h westward flight, we know that jet lag symptoms contributed to the physiological alterations noted the day after arrival in the hot/humid climate. Indeed, Atkinson and Reilly (1996) reported that most components of sports performance exhibit a rhythmic variation during the day. These jet lag adjustments, however, may have been minimized by the fact that the triathletes usually trained in the morning (8-11 am) and the early evening (4-7 pm) in thermoneutral conditions. They performed the study tests at 10:30 am in the tropical climate, which corresponded to $4: 30 \mathrm{pm}$ in thermoneutral conditions (France). Although by the 8 th and the 14th day it is likely that any jet lag symptoms had disappeared, as the main retraining shift rate after a westward flight has been demonstrated to be about 92 min $\cdot$ day $^{-1}$ (Aschof et al., 1975), we should assume that slight persisting symptoms could not have had a physiological effect at the 8th and the 14th day.

Two days after arrival, the performance was significantly lower $\left(1 \mathrm{~km} \cdot \mathrm{h}^{-1}\right.$ lower, a $5 \%$ decrease) than that noted in thermoneutral conditions. The HR was significantly greater in T2 than in TN, T8 and T14, and sweat rate and body mass loss in T2 were significantly lower than in T8 and T14. This performance decrease, which was accompanied by a mean HR increase (17 bpm, $12.5 \%$ increase), greater mean temperature and mean sweat rate, reflected the high stress imposed 
by the combined tropical climate and jet lag. Concomitantly with the lower sweat rate, we noted a significantly greater mean temperature in T2 compared with other trials, indicating that the acclimatization process had not yet started since a drop in the sweating threshold is the primary change caused by acclimation (Shapiro et al., 1998). We may thus suppose that hyperthermia, which might have also been related to jet lag, was the primary factor that limited performance in T2. Indeed, dehydration and hyperthermia have separately been demonstrated to impair performance (Maughan, 1998).

At the 8th day of acclimatization, performance was significantly lower $\left(0.44 \mathrm{~km} \cdot \mathrm{h}^{-1}\right.$, a $2.3 \%$ decrease $)$ than that noted in thermoneutral conditions. This performance was accompanied by higher mean temperature and mean sweat rate and greater body mass loss after versus before exercise. However, we noted that HR was the same as in TN and that mean HR was significantly greater than in T14. These findings suggest that heat acclimatization was underway but not finished at the $8^{\text {th }}$ day. Moreover, the significantly greater HR observed in T8 than in thermoneutral conditions from $\mathrm{HR}_{\mathrm{A}}$ to $\mathrm{HR}_{\max }$ strongly suggests that the stress induced by tropical conditions was not entirely overcome at maximal intensity in T8.

At the 14th day of acclimatization, performance was significantly lower $(0.38$ $\mathrm{km} \cdot \mathrm{h}^{-1}$, a $2 \%$ decrease) than that noted in thermoneutral conditions. This performance decrease was accompanied by a significantly lower mean HR compared with the other trials, a mean sweat rate and body mass loss significantly greater than in T2, and a mean temperature lower than in T2. Although performance was still impaired in $\mathrm{T} 14$ in comparison with $\mathrm{TN}$, we noted no significant difference at the end of exercise in temperature between T14 and TN and, concomitantly, HR was significantly lower before $\mathrm{HR}_{\mathrm{A}}$ in $\mathrm{T} 14$ than in $\mathrm{TN}$. These results suggest that another stage reached in the acclimatization process induced a better thermoregulatory and cardiovascular efficiency. This may be explained by the fact that for the same external work, following acclimation, heart rate becomes more efficient (Horowitz, 1996).

The temperature and sweat rate during recovery, however, were greater in T14 than in T2, demonstrating that the heat strain induced by tropical conditions was not entirely overcome after 14 days of acclimatization.

The results of this study are surprising in light of earlier research. Nielsen (1998) compared different acclimation procedures (60-90 min of exercise at 50$60 \% \mathrm{VO}_{2 \max }$ in dry heat versus $45-51 \mathrm{~min}$ at $40-50 \% \mathrm{VO}_{2 \max }$ in humid heat) and found that the physiological adaptations were similar and that acclimation was achieved in dry or humid heat after 8-12 consecutive days. Another study demonstrated that nearly complete exercise heat-acclimation for hot/dry environment occurs after 7 days of exposure and that acclimation is faster in well-trained subjects (Pandolf et al., 1977), this last characteristic being the case of the subjects in the present study. Moreover, continuous daily 100-min exercise has been reported to facilitate the heat acclimation process (Lind and Bass, 1963) and the triathletes in the present study performed $120 \mathrm{~min}$ of exercise (approximately $50 \mathrm{~min}$ running and $70 \mathrm{~min}$ swimming at $60-80 \% \mathrm{VO}_{2 \max }$ ) every day.

As noted by Shapiro et al. (1998), however, the problem of exposure to hot/ wet climates lies in the fact that the high required evaporative cooling $\left(\mathrm{E}_{\mathrm{req}}\right)$ exceeds the evaporative capacity of the environment $\left(\mathrm{E}_{\max }\right)$. Thus, in situations where $\mathrm{E}_{\max }$ is limited, adherence to the strategy used under hot/dry climate (i.e., reducing 
heat storage by increasing the sweating rate) creates a physiological disadvantage (Shapiro et al., 1998) that results in severe dehydration. The only way to achieve a match between heat gain and heat dissipation during outdoor exercise is by reducing the metabolic heat production, thus the intensity. Many studies have shown that following acclimation, there is at least a $5 \%$ reduction in metabolic heat production (Sawka et al., 1983). This hypothesis could explain the better thermoregulatory control observed at T8 and T14.

The results of the present study are in accord with a recent study that reported that acclimation was not completely achieved after 10 daily exposures to humid heat with a NBC suit (Shapiro et al., 1998). Aoyagi et al. (1994) also demonstrated that people who are exposed to hot/wet climate will benefit very little from hot/dry acclimation. We may therefore assume that in the present study, high sweat rate and body mass loss impaired performance more than hyperthermia on the 8th and 14th days. The mean sweat rate at the end of exercise in T8 and T14 was, respectively, 2.7 and $1.9 \mathrm{~L} \cdot \mathrm{h}^{-1}$, significantly greater than in $\mathrm{T} 2\left(1.2 \mathrm{~L} \cdot \mathrm{h}^{-1}\right)$ and similar to that noted by Booth et al. (1998) during a 30-min treadmill test performed as fast as possible. This high sweat rate certainly induced severe dehydration, which would in part explain the lower performance noted in T8 and T14 in comparison with TN. Indeed, it is well known that one of the classical adjustments in the acclimation process is an increase in sweat rate (Pandolf, 1998; Roberts et al., 1977).

Recently, Nielsen (1996) theoretically calculated the influence of hot/wet conditions on performance in the 1996 Olympics in Atlanta. She demonstrated that a runner who could complete a marathon in $2 \mathrm{~h} 20 \mathrm{~min}$ in cool conditions would not be able to run faster than $3 \mathrm{~h} 20$ min under these thermoregulatory constraints. While the effect on performance in the present study was less than these theoretical calculations suggest, the results demonstrated a real reduction in capacity when exercise is performed under hot/wet conditions, even during short intense exercise performed by young well-trained triathletes after 14 days of acclimatization. Furthermore, Galloway and Maughan (1997) showed that thermoregulatory stress was increased with both time and intensity. Questions then arise as to whether a longer acclimatization period would have overcome the physiological strain induced by tropical climate in the present study and, more generally, whether complete acclimation at exercise is possible under hot/wet conditions. It has been demonstrated that competitive athletes expected to participate in an event involving heat stress should acclimate/train in the heat for at least 5 days before participation to help maximize their performance (Pandolf, 1998). But our results strongly suggest that more days of acclimatization are certainly needed to permit athletes to perform as well as in thermoneutral conditions.

In summary, the present study demonstrates that 14 days under hot/wet conditions are insufficient to acclimatize well-trained athletes. The hot/wet climate impaired performance and physiological parameters, certainly in relation with both hyperthermia and dehydration, and this impairment was still evident after 14 days. Nevertheless, signs of adaptation to the heat were evident on the 14th day and performance of a maximal aerobic test on this day tended to be closer to that noted in thermoneutral conditions. Based on these results, we suggest that competitive athletes planning to participate in an aerobic event involving hot/wet stress should acclimatize for a longer period than that currently recommended. 


\section{References}

Aoyagi, Y., McLellan, T.M., and Shepard, R.J. (1994). Effect of training and acclimation on heat tolerance in exercising men wearing protective clothing. Eur. J. Appl. Physiol. 68: 234-245.

Armstrong, L.E., and Maresh, C.M. (1991). The induction and decay of heat acclimatisation in trained athletes. Sports. Med. 12: 302-312.

Aschoff, J., Hoffman, K., Polh, H., and Wever, R. (1975). Re-entrainment of circadian rythms after phase-shifts of the zeitgeber. Chronobiologia 2: 23-78.

Atkinson, G., and Reilly, T. (1996). Circadian variation in sports performance. Sports. Med. 21: 292-312.

Beaver, W.L., Wasserman, K., and Whipp, B.J. (1986). A new method for detecting anaerobic threshold by gas exchange. J. Appl. Physiol. 60: 2020-2027.

Booth, J., Marino, F., and Wrad, J.W. (1998). Improved running performance in hot humid conditions following the whole body pre-cooling. J. Appl. Physiol. 29: 943-949.

Bricknell, M.C. (1997). An evaluation of infra-red tympanic thermometry for thermal physiology research. J. R. Arm. Med. Corps. 143: 152.

Cheung, S.C., and McLellan, T.M. (1998a). Influence of short term aerobic training and hydration status on tolerance during uncompensable stress. J. Appl. Physiol. 78: 50-58.

Cheung, S.C., and McLellan, T.M. (1998b). Heat acclimation, aerobic fitness, and hydration effects on tolerance during uncompensable stress. J. Appl. Physiol. 84: 17311739.

Du Bois, D., and Du Bois, E.F. (1916). Clinical calorimetry: a formula to estimate the approximate surface area if height and weight be known. Arch. Intern. Med. 17: 863-871.

Galloway, S.D.R., and Maughan, R.J. (1997). Effects of the ambient temperature on the capacity to perform prolonged exercise. Med. Sci. Sports. Exerc. 29: 1240-1249.

Horowitz M. (1996). The beneficial effects of heat acclimation and exercise training on cardiac performance and cardiovascular efficiency in stressful environment. In: Shapiro, Y., Moran, D.S., Epstein, Y. (Eds.), Environmental ergonomics: Recent progress and new frontiers, pp. 3-7. London: Freund Publishing House.

Hue, O., Le Gallais, D.,Chollet, D., and Préfaut, C. (2000). Ventilatory threshold and maximal oxygen uptake in triathletes. Can. J. Appl. Physiol. 25: 102-113.

Keney, W.L. (1998). Heat flux and storage in hot environments. Int. J. sports. Med. 19: S92-S95.

Léger, L.A., and Boucher, R. (1980). An indirect continuous running multistage field test: The Université de Montréal track test. Can. J. Sports. Sci. 5: 77-84.

Lind, A.R., and Bass, D.E. (1963). Optimal exposure time development of acclimatization to heat. Fed. Prod. 11: 60-65

Manfredini, R., Manfredidni, F., Fersini, C., and Coconi, F. (1998). Circadian rhythms, athletic performance, and jet lag. Br. J. Sports. Med. 32: 101-106.

Margaria, R.P., Cerretelli, P., Aghemo, P., and Sassi, J. (1963). Energy cost of running. J. Appl. Physiol. 18: 367-370.

Maughan, R.J., and Shirrefs, S.M. (1998). Dehydration, rehydration and exercise in the heat: Concluding remarks. Int. J. sports. Med. 19: S167-S168.

Morris, J.G., Nevill, N.E., Lakomy, H.K.A., Nicholas, C., and Williams, C. (1998). Effect of a hot environment on performance of prolonged, intermittent, high-intensity shuttle running. J. Sports. Sci. 16: 677-686. 
Nielsen, B. (1996). Olympics in Atlanta: A fight against physics. Med. Sci. Sports. Exerc. 28: 665-668.

Nielsen, B. (1998). Heat acclimation - mechanisms of adaptation to exercise in the heat. Int. J. Sports. Med. 19 : S154-S156.

Pandolf, K.B., Burse, R.L., and Goldman, R.F. (1977). Role of physical fitness in heat acclimatization, decay and reinduction. Ergonomics 20: 399-408.

Pandolf, K.B., Sawka M.N., and Gonzales, R.R. (Eds.) (1988). Human performance physiology and environmental medicine at terrestrial extremes. Indianapolis, IN: Benchmark Press, Inc.

Pandolf, K.B. (1998). Time course of heat acclimation and its decay. Int. J. Sports. Med. 19: S157-S160.

Pilardeau, P. (1995). Biochimie et Nutrition des activités Physiques 2 : Eau et électrolytes, vitamines et oligo-éléments. Effets de l'exercise sur le métabolisme. Paris: Mason éditions.

Robert, M.F., Wenger, C.B., Stolwijk, J.A.J., and Nadel, E.R. (1977). Skin blood flow and sweating changes following exercise training and heat acclimation. J. Appl. Physiol. 43: 133-137.

Sawka, M.N., Pandolf, K.B., Avellini, B.A., and Shapiro, Y. (1983). Does heat acclimation lower the rate of metabolism elicited by muscular exercise? Aviat. Space. Environ. Med. 54: 27-31.

Sawka, M.N., Wenger, C.B., and Pandolf, K.B. (1996). Thermoregulatory responses to acute exercise-heat stress and heat acclimation. In: Fregly, M.J., Blatteis, C.M., (Eds.), Handbook of physiology: Environmental physiology, pp. 157-186. New-York: Oxford University Press.

Sawka, M.N., Convertino, V.A., Eichner, E.R., Schnieder, S.M., and Young, A.J. (2000). Blood volume: Importance and adaptation to exercise training, environmental stresses, and trauma/sickness. Med. Sci. Sports. Exerc. 32(Suppl. 2): 332-348.

Shapiro, Y., Moran, D., and Epstein, Y. (1998). Acclimatization strategies: preparing for exercise in the heat. Int. J. Sports. Med. 19: S161-S163. 